\title{
Rhinopharyngeal Retrograde Clearance Induces Less Respiratory Effort and Fewer Adverse Effects in Comparison With Nasopharyngeal Aspiration in Infants With Acute Viral Bronchiolitis
}

\author{
Gabriela R Gomes PT MSc, Fernanda PG Calvete PT, Gabriela F Rosito PT, and \\ Márcio VF Donadio PT PhD
}

\begin{abstract}
BACKGROUND: Acute viral bronchiolitis is an inflammatory disease of the lower respiratory tract. This study aimed to compare the immediate effects of retrograde rhinopharyngeal clearance with nasopharyngeal aspiration in children admitted with acute viral bronchiolitis. METHODS: This was a randomized controlled clinical trial with children admitted for acute viral bronchiolitis up to 12 months old. Subjects were divided into a nasopharyngeal aspiration group and a clearance group, submitted to retrograde rhinopharyngeal clearance with physiological solution $(0.9 \%)$ instillation. In both groups, there were 3 evaluations on the same day (data collections 1, 2, and 3), including cardiorespiratory parameters, clinical score of respiratory dysfunction, and adverse effects. RESULTS: One hundred children were included, with no statistical differences between groups regarding the characteristics of the sample. There was a significant reduction $(P<.05)$ in heart rate in data collections 1 and 2 after 10 and $30 \mathrm{~min}$. The number of episodes of nasal bleeding (28 vs 1) and vomiting (11 vs 7) was higher in the aspiration group compared with the clearance group. Children classified as moderate showed a significant reduction of retractions $(100 \%$ vs $84.6 \%)$ and nasal bleeding $(44.8 \%$ vs $0 \%)$. An increase of 6.7 and $19.5 \%$ in wheezing and retractions, respectively, was shown for the aspiration group, whereas the clearance group showed only 4.6\% for both parameters. CONCLUSIONS: The use of retrograde rhinopharyngeal clearance in the management of infants with acute viral bronchiolitis can be an alternative for the clearance of the upper airways, since it showed immediate positive effects on the occurrence of complications and signs of respiratory effort compared with nasopharyngeal aspiration. Children classified with a moderate clinical score appear to benefit the most. (ClinicalTrials.gov registration NCT02460614.) Key words: acute viral bronchiolitis; children; clearance; respiratory physiotherapy. [Respir Care 2016;61(12):1613-1619. () 2016 Daedalus Enterprises]
\end{abstract}

\section{Introduction}

Acute viral bronchiolitis is a lower respiratory tract inflammatory disease, with a viral etiology, where the respiratory syncytial virus is the most prevalent agent. ${ }^{1,2}$

\footnotetext{
Ms Gomes is affiliated with Pontifícia Universidade Católica do Rio Grande do Sul (PUCRS), Porto Alegre, RS, Brazil. Ms Calvete and Ms Rosito are affiliated with the School of Nursing, Nutrition, and Physiotherapy, PUCRS, Porto Alegre, RS, Brazil. Dr Donadio is affiliated with the Centro Infant, Institute of Biomedical Research, PUCRS, Porto Alegre, RS, Brazil.
}

The authors have disclosed no conflicts of interest.
Acute viral bronchiolitis mainly affects children in their first 2 years of life, with a peak incidence at 6 months old. It is the most common disease in pediatric hospitalizations, especially in winter periods, with $90 \%$ of children infected with respiratory syncytial virus in its first 2 years of life and $40 \%$ presenting an infection in the lower respiratory

\footnotetext{
Correspondence: Márcio Donadio PT PhD, Centro Infant, Institute of Biomedical Research (IPB), Avenida Ipiranga, 6690, $2^{\circ}$ Andar, Porto Alegre, Rio Grande do Sul, CEP 90610-000, Brazil. E-mail: mdonadio@pucrs.br.
}

DOI: $10.4187 /$ respcare. 04685 
tract. ${ }^{3}$ Generally, it is a self-limiting disease, but it produces significant morbidity in infants or children with chronic diseases. ${ }^{4}$

The pathophysiological changes begin with the infection of the upper airways, evolving into an inflammatory reaction in the lower respiratory tract, causing obstruction and increased work of breathing. ${ }^{4}$ Thus, the basic principles of treatment are supportive therapy with supplemental oxygen, administration of fluids, rest, proper nutrition, and guidance for parents. ${ }^{3}$ The use of other treatments, including chest physiotherapy, varies according to the disease severity and is still controversial. In general, chest physiotherapy in pediatrics has as its main objectives the removal of secretions, improvement of gas exchange, and reduction of the respiratory effort. ${ }^{5}$

The use of chest physiotherapy in acute viral bronchiolitis has been evaluated and discussed in several studies, ${ }^{6-9}$ analyzing different techniques and outcomes, but there is still no consensus. In the last Cochrane review, ${ }^{5}$ results indicated that outcomes such as hospitalization and duration of oxygen therapy do not benefit from the use of physiotherapy techniques, especially percussion, vibration with postural drainage, and prolonged slow exhalation. Regardless of conflicting data in the literature, some acute viral bronchiolitis patients may need airway clearance (ie, removal of secretions). Usually, chest physiotherapy and nasopharyngeal aspiration are the main resources available, and in clinical practice, the latter is widely used in these cases. ${ }^{10}$ However, considering that nasopharyngeal aspiration is an invasive procedure, the American Association for Respiratory Care recommends that suction of secretions should be initiated only in response to clinical signs and symptoms such as worsening of the respiratory distress, signs of obstruction, agitation, and decrease of saturation, since its use can cause damage to the respiratory tract, inducing laryngeal spasm, vagal bradycardia, atelectasis, increased intracranial pressure, and local infection. ${ }^{11}$

Thus, the search for strategies that can contribute to airway clearance and improve respiratory distress in these cases is a relevant clinical and research problem. One possible alternative in such cases could be the retrograde rhinopharyngeal clearance technique with saline instillation. ${ }^{8,12}$ This technique consists of a forced inspiratory maneuver intended for clearing the nasopharynx, with or without local instillation of a therapeutic solution. To date, only one study has evaluated the use of retrograde rhinopharyngeal clearance, demonstrating a clinical score and wheezing reduction that lasted up to $72 \mathrm{~h}$ after the intervention. ${ }^{8}$

Therefore, considering the high prevalence of acute viral bronchiolitis in pediatric admissions, the pathophysiological changes resulting from inflammation of the airways (increased work of breathing with consequent

\section{QUICK LOOK}

\section{Current knowledge}

Acute viral bronchiolitis is an inflammatory disease of the lower respiratory tract that affects children in their first 2 years of life, and it is the most common disease in pediatric hospitalizations. The use of the retrograde rhinopharyngeal clearance technique with saline instillation may represent an alternative to nasopharyngeal aspiration in the treatment of children hospitalized for acute viral bronchiolitis.

\section{What this paper contributes to our knowledge}

The use of the retrograde rhinopharyngeal clearance technique in the clinical management of infants hospitalized by acute viral bronchiolitis led to fewer complications and signs of respiratory effort compared with nasopharyngeal aspiration. Children classified with a moderate clinical score benefited the most.

worsening of symptoms), the frequent use of nasopharyngeal aspiration in hospital practice, and its risks as an invasive procedure, it is justified to further study the retrograde rhinopharyngeal clearance as an alternative in the clinical management of infants with acute viral bronchiolitis. Thus, this study aimed to evaluate the immediate effects of the retrograde rhinopharyngeal clearance technique compared with nasopharyngeal aspiration in infants hospitalized with acute viral bronchiolitis.

\section{Methods}

This was a randomized controlled clinical trial conducted in the winter of 2013. Children with a clinical diagnosis of acute viral bronchiolitis, $\leq 12$ months old, and hospitalized were included. Children were excluded if one of the following criteria were present: history of lung disease related to prematurity (bronchopulmonary dysplasia), heart disease, chronic lung diseases (cystic fibrosis), bronchopneumonia or associated pneumonia, unstable hemodynamics (ARDS or sepsis), subcutaneous edema, admission to the ICU, tracheostomy, or the need for mechanical ventilation and associated neurological disease. The sample size was estimated based on the effect of the techniques used on heart rate variation. Data from the first 20 subjects enrolled were used. Considering an SD value of 14.6, adopting a significance level of 0.05 , a power of $90 \%$ and a minimum difference of 10.0, the sample size was estimated to be approximately 47 individuals for each experimental group.

The study was approved by the ethics committee of the university (protocol 10/05235). After inclusion and exclu- 


\section{Rhinopharyngeal Clearance in Infants With Bronchiolitis}

sion criteria were checked and parents or legal guardians signed the informed consent form, subjects were randomly assigned using software to 2 groups: the nasopharyngeal aspiration group, submitted to the aspiration of nasopharynx, and the clearance group, in which the retrograde rhinopharyngeal clearance technique was performed. All children included in the study were in the first $48 \mathrm{~h}$ of admission. Both the aspiration and clearance groups underwent the procedures and evaluations at 3 different moments of the study: data collection 1, performed in the early morning; data collection 2, performed in the early afternoon; and data collection 3 , performed in the evening. In each data collection, separated by approximately $4 \mathrm{~h}$, the following parameters were evaluated: heart rate, breathing frequency, $\mathrm{S}_{\mathrm{pO}_{2}}$ with oxygen use, $\mathrm{S}_{\mathrm{pO}_{2}}$ in room air, respiratory distress signs (chest retractions, nasal flaring), and clinical severity score. ${ }^{13}$ The clinical score includes the evaluation of variables such as heart rate, breathing frequency, chest retractions, presence of wheezing, pulmonary auscultation, and cyanosis. Each variable is graduated from 0 (absent) to 3 (severe), and the final score is categorized into 3 levels: mild (1-3), moderate (4-7), and high ( $8-14)$. $^{13}$ These variables were recorded at 3 times: time 0 , before the procedure; time 1, 10 min after performing the procedure; and time 2, $30 \mathrm{~min}$ after the procedure. Each procedure, nasopharyngeal aspiration or retrograde rhinopharyngeal clearance, lasted around $5 \mathrm{~min}$. In both groups, all other routine and therapeutic procedures were usually performed according to the prescription. The occurrence of adverse events (vomiting, nasal bleeding, and sweating) was assessed throughout the day of collection by consulting clinical records and checking with members of the nursing staff.

Subjects in the nasopharyngeal aspiration group underwent aspiration of the nasopharynx, following the unit routine, by the nursing staff technician responsible for the subject. The procedure consisted in the introduction of a sterile aspiration catheter (Mark Med, São Paulo, Brazil) number 06 or 08 (according to the patient's size) to the nasopharynx. The catheter was connected to an extension, and the technician, using latex gloves, carefully introduced it through the nasal orifice of the subject. The depth of suction was estimated based on the distance measured between the tip of the subject's nose and the tip of the subject's ear lobe. A negative (vacuum) pressure, neonates $(60-80 \mathrm{~mm} \mathrm{Hg})$ and infants $(80-100 \mathrm{~mm} \mathrm{Hg})$, promoted the suction of secretion from the airways. A $0.9 \%$ saline instillation was used for humidification before the procedure.

In the clearance group, subjects were submitted to the retrograde rhinopharyngeal clearance technique, performed by an experienced physical therapist. The retrograde rhinopharyngeal clearance is based on the inspiratory reflex that follows the slow and prolonged expiration (passive expiratory technique performed by a slow thoracoabdominal compression that begins at the end of a spontaneous inhalation and continues until the expiratory reserve volume) provoked by cough or crying. At the end of the expiratory time, the child's mouth was closed by the hand of the therapist (raising the lower jaw), which accompanied the expiratory movement, inducing the child to perform a nasal aspiration. The saline instillation was performed before the maneuver, resulting in the inhalation of this substance during the forced inspiratory movement, contributing to the nasopharyngeal clearance.

The normality of data was evaluated using the Kolmogorov-Smirnov test. Considering that a symmetrical distribution was found, data were expressed as mean and SD. Categorical variables were expressed as absolute and relative frequency. The differences between continuous variables between groups were evaluated using the Student $t$ test, whereas categorical variables were assessed using the Pearson chi-square test. The significance level was set at $P<.05$. All analyses were performed using SPSS 17.0 (SPSS, Chicago, Illinois).

\section{Results}

The present study included 114 hospitalized infants diagnosed with acute viral bronchiolitis, randomly divided into 2 groups (aspiration and clearance). From the total sample, 14 children were excluded because they presented at least one of the exclusion criteria. Table 1 shows the characteristics of the sample, with no statistical differences between the groups regarding age, sex, weight at admission, and weight at birth. In both groups, the infants were born with weight and gestational age considered ideal. The respiratory syncytial virus was identified in $68 \%$ of cases in the aspiration group and $54 \%$ in the clearance group.

Figure 1 shows the variation of the main parameters evaluated at each time point from different collections, separated into aspiration and clearance groups. In Figure $1 \mathrm{~A}$, results show that after 10 and $30 \mathrm{~min}$, both in collection $1(P=.002$ and $P=.02$, respectively) and in collection $2(P=.038$ and $P=.02$, respectively), there was a significant heart rate reduction in children submitted to the retrograde rhinopharyngeal clearance when compared with aspiration. The variation of the breathing frequency (Fig. 1B) in response to the techniques presented no statistically significant changes. Similarly, no significant differences were observed for oxygen saturation, both in room air (Fig. 1D) and with supplementation (Fig. 1C), as well as for the clinical scores applied (Fig. 1, E and F).

Regarding the adverse effects evaluated, the number of nasal bleeding episodes (aspiration group $=28$, clearance group $=1$ ) and vomiting (aspiration $=11$ and clearance $=7$ ) on the day of the study were higher in subjects 
Table 1. Characterization of the Studied Sample

\begin{tabular}{|c|c|c|c|}
\hline Characteristic & $\begin{array}{l}\text { Aspiration } \\
\text { Group } \\
(n=50)\end{array}$ & $\begin{array}{c}\text { Clearance } \\
\text { Group } \\
(n=50)\end{array}$ & \\
\hline Age, mean \pm SD months & $4.78 \pm 2.98$ & $4.80 \pm 2.92$ & .97 \\
\hline Male sex, $\%$ & 48.4 & 51.6 & .67 \\
\hline Admission weight, mean \pm SD kg & $6.89 \pm 2.03$ & $6.70 \pm 1.87$ & .63 \\
\hline Weight Z-score $\times$ age, mean \pm SD & $0.33 \pm 1.34$ & $0.08 \pm 1.27$ & .34 \\
\hline Birth weight, mean $\pm \mathrm{SD} \mathrm{kg}$ & $3.20 \pm 0.57$ & $3.21 \pm 0.63$ & .95 \\
\hline \multicolumn{3}{|l|}{ Birth weight classification, \% } & .79 \\
\hline Low $(<2,500 \mathrm{~g})$ & 10.2 & 12.0 & \\
\hline Normal $(>2,500 \mathrm{~g}$ and $<4,000 \mathrm{~g})$ & 79.6 & 74.0 & \\
\hline Macrosomia $(>4,000 \mathrm{~g})$ & 10.2 & 14.0 & \\
\hline \multicolumn{3}{|l|}{ Gestational age, \% } & \\
\hline Pre-term $(<37 \mathrm{wk})$ & 12.5 & 18.4 & \\
\hline Term $(>37$ wk and $<42$ wk) & 81.3 & 81.6 & \\
\hline Post-term ( $>42 \mathrm{wk})$ & 6.3 & 0 & \\
\hline \multicolumn{3}{|l|}{ First viral episode, $\%$} & . \\
\hline Yes & 68.0 & 72.0 & \\
\hline No & 32.0 & 28.0 & \\
\hline $\begin{array}{l}\mathrm{S}_{\mathrm{pO}_{2}} \text { room air admission, } \\
\text { mean } \pm \mathrm{SD} \%\end{array}$ & $95.3 \pm 3.7$ & $95.5 \pm 1.7$ & .72 \\
\hline $\begin{array}{c}\text { Breathing frequency admission, } \\
\text { mean } \pm \text { SD breaths } / \text { min }\end{array}$ & $51.7 \pm 11.3$ & $51.6 \pm 11.0$ & .93 \\
\hline
\end{tabular}

from the aspiration group when compared with the clearance group (Fig. 2). When infants were analyzed separated by the clinical severity score, ${ }^{13}$ we could see that children classified as mild presented no significant improvement in the occurrence of chest retractions, wheezing, and nasal bleeding $10 \mathrm{~min}$ after the techniques were performed. However, in infants classified as moderate, there was a significant reduction in the occurrence of chest retractions and nasal bleeding in the clearance group as compared with the aspiration group. As for the children classified with a high clinical score, there was a significant decrease in the clearance group only in the number of nasal bleeding episodes. These data are presented in Table 2.

In addition, regarding the effects on parameters of respiratory effort, Figure 3 shows the effect of nasopharyngeal aspiration and retrograde rhinopharyngeal clearance on the increase of wheezing or the presence of chest retractions 10 min after each procedure was performed. Results demonstrate an increase of $6.7 \%$ in the number of infants presenting wheezing and of $19.5 \%$ presenting chest retractions $10 \mathrm{~min}$ after nasopharyngeal aspiration was performed, whereas an increase of only $4.6 \%$ (for both parameters) was seen after retrograde rhinopharyngeal clearance was performed.

\section{Discussion}

This study evaluated the effects of a noninvasive respiratory therapy technique, rhinopharyngeal retrograde clearance, compared with nasopharyngeal aspiration (an invasive procedure) on respiratory effort parameters and adverse effects in children hospitalized with a diagnosis of acute viral bronchiolitis. In general, the use of the retrograde rhinopharyngeal clearance technique resulted in a significantly lower increase in heart rate, decrease in the occurrence of nose bleeding and vomiting episodes, and a reduction in respiratory effort parameters, such as chest retractions and wheezing. To date, except for a case report, ${ }^{12}$ there is only one study evaluating the effects of retrograde rhinopharyngeal clearance in infants with acute viral bronchiolitis, which demonstrated a clinical score decrease, including variables such as wheezing and chest retractions. ${ }^{8}$ However, it should be noted that this study used retrograde rhinopharyngeal clearance together with other airway clearance techniques. Therefore, to our knowledge, this study is the first to independently assess the acute effects of the retrograde rhinopharyngeal clearance technique in infants with acute viral bronchiolitis.

In our study, in each data collection, the signs of respiratory effort, such as breathing frequency, heart rate, presence of wheezing, and chest retractions were evaluated before and after each procedure. The results show that there is a reduction in heart rate after retrograde rhinopharyngeal clearance was performed (collections 1 and 2), whereas no change was observed in the aspiration group. These findings are consistent with previous studies ${ }^{9,14}$ and indicate that heart rate reduction may be related to the reduction of respiratory distress. The mobilization of secretions with the use of less manipulative techniques, as already shown for the prolonged slow expiration, ${ }^{14}$ may have a role in this effect. Regarding the breathing frequency, as shown in other studies, $, 7,8$ there was no significant difference in both groups, although there is evidence in the literature that showed a reduction in the breathing frequency after the use of chest physiotherapy techniques. ${ }^{15,16}$ In general, the use of retrograde rhinopharyngeal clearance, as well as other respiratory therapy techniques, did not induce cardiorespiratory distress in children with acute viral bronchiolitis. Moreover, the present results showed an increase of 6.7 and $19.5 \%$ of children who started to have wheezing and retractions, respectively, after the nasopharyngeal aspiration. On the other hand, in the clearance group, this increase was only $4.6 \%$ for both wheezing and retractions. These results support the idea of a decrease in respiratory effort parameters after respiratory physiotherapy is performed, particularly when using more contemporary techniques. ${ }^{8,14,16}$ 

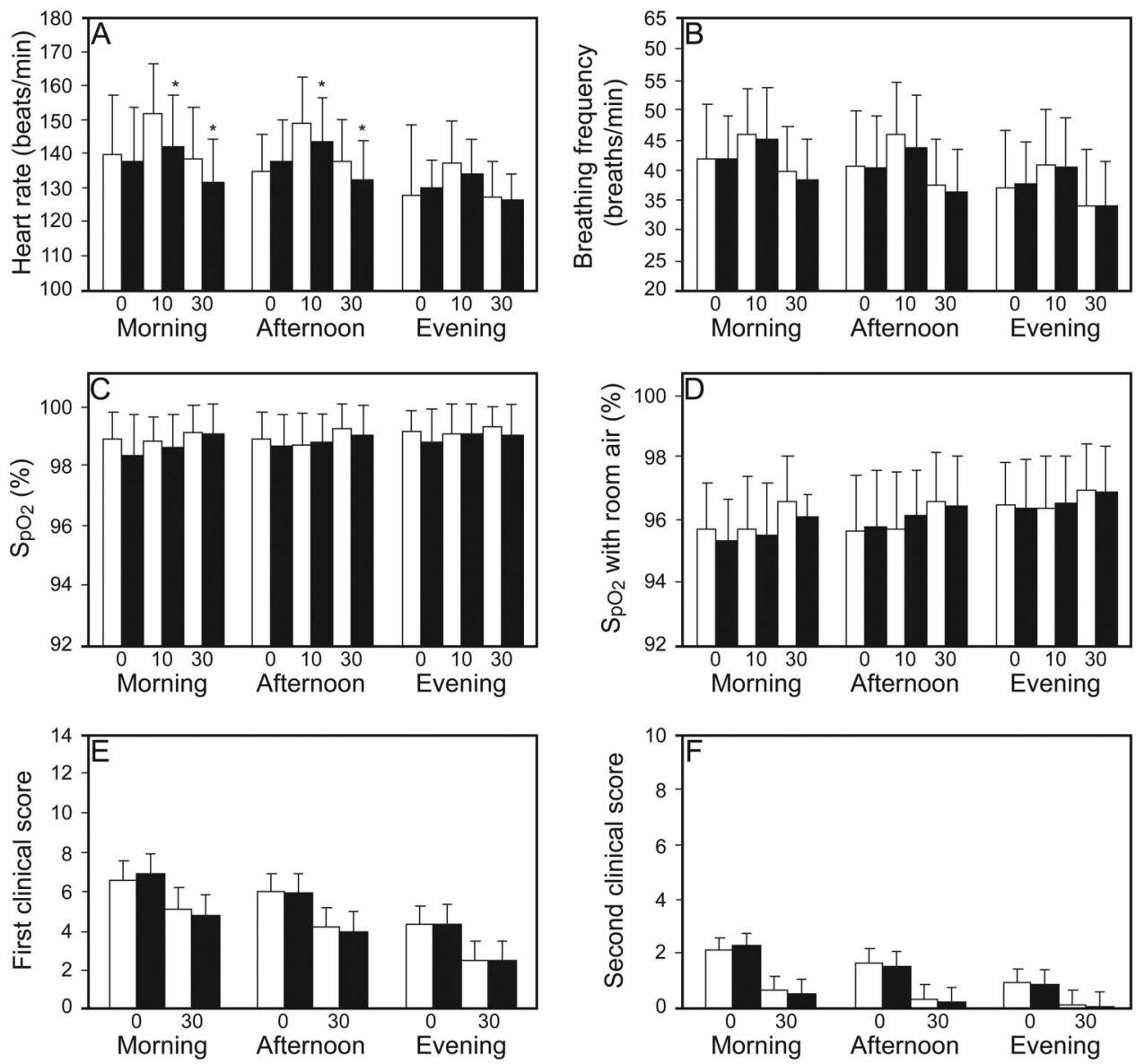

Fig. 1. Main parameters studied at the different time points (before [0] and 10 and $30 \mathrm{~min}$ after) and evaluations (performed in the morning, afternoon, and evening). A: Heart rate. B: Breathing frequency. C: $\mathrm{S}_{\mathrm{pO}_{2}}$ with oxygen. D: $\mathrm{S}_{\mathrm{pO}_{2}}$ with room air. E: First clinical score. F: Second clinical score. ${ }^{*} P<.05$. White bars, aspiration; black bars, clearance.
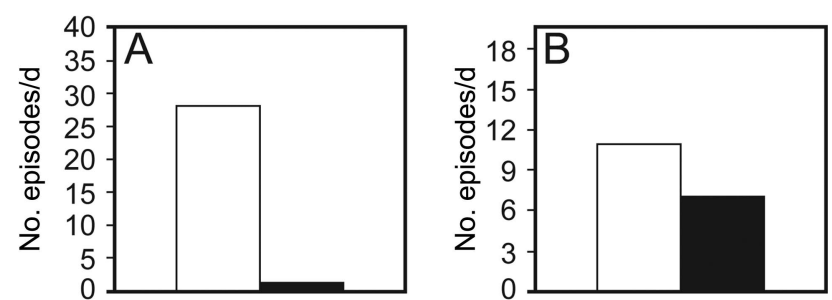

Fig. 2. Number of episodes of nasal bleeding (A) and vomiting (B) in the aspiration and clearance groups. White bars, aspiration; black bars, clearance.

Regarding the main adverse effects assessed, the results of the present study show that the number of nasal bleeding and vomiting episodes, during the day of collection, were higher in the aspiration group when compared with the clearance group. The presence of complications after a respiratory physiotherapy intervention was performed in infants with acute viral bronchiolitis was previously reported in only one study, ${ }^{17}$ in which a higher rate of vomiting during the session in children submitted to airway clearance maneuvers (increased exhalation technique and
Table 2. Influence of the Severity of Bronchiolitis, According to the Wood Clinical Score, on the Effects of Aspiration or Retrograde Rhinopharyngeal Clearance on the Occurrence of Chest Retraction, Nasal Bleeding, and Wheezing 10 Min After the Procedures

\begin{tabular}{|c|c|c|c|c|c|c|}
\hline & \multicolumn{2}{|c|}{ Mild } & \multicolumn{2}{|c|}{ Moderate } & \multicolumn{2}{|c|}{ High } \\
\hline & $\begin{array}{c}\text { ASP } \\
(n=2)\end{array}$ & $\begin{array}{c}\text { CLE } \\
(n=2)\end{array}$ & $\begin{array}{c}\text { ASP } \\
(n=29)\end{array}$ & $\begin{array}{c}\text { CLE } \\
(n=26)\end{array}$ & $\begin{array}{c}\text { ASP } \\
(n=11)\end{array}$ & $\begin{array}{c}\text { CLE } \\
(n=12)\end{array}$ \\
\hline Chest retractions & 50.0 & 50.0 & 100.0 & $84.6 *$ & 100.0 & 100.0 \\
\hline Nasal bleeding & 50.0 & 0 & 44.8 & $0^{*}$ & 63.6 & $8.3^{*}$ \\
\hline Wheezing & 0 & 50.0 & 62.1 & 46.2 & 36.4 & 75.0 \\
\hline $\begin{array}{l}\text { Data are expressed as } \\
\text { high (8-14). } \\
\text { * Significant differeno } \\
\text { chi-square test. } \\
\text { ASP }=\text { aspiration gro } \\
\text { CLE }=\text { clearance grol }\end{array}$ & $\begin{array}{l}\text { percentage } \\
\text { up }(P<.05)\end{array}$ & $\begin{array}{l}\text { s }(\%) \text {. The } \\
\text { when com }\end{array}$ & $\begin{array}{l}\text { score levels } \\
\text { pared with th }\end{array}$ & re: mild (1- & $\begin{array}{l}\text { ), moderate } \\
\text { group using }\end{array}$ & $\begin{array}{l}\text { (4-7), and } \\
\text { Pearson }\end{array}$ \\
\hline
\end{tabular}

assisted cough) was identified through reports from physiotherapists. However, taken as a whole, studies evaluating the effects of respiratory physiotherapy in children with 

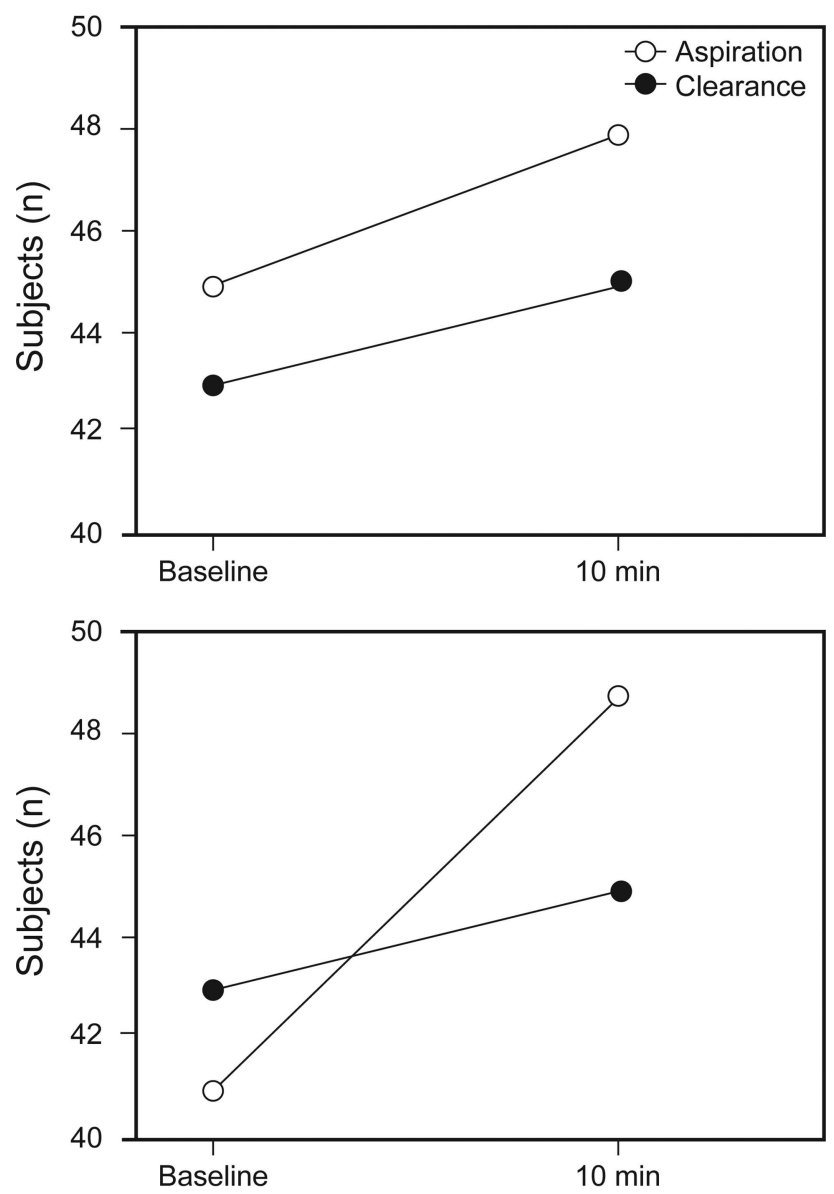

Fig. 3. Effect of aspiration and retrograde rhinopharyngeal clearance on the increase of wheezing $(A)$ or the presence chest retractions (B) 10 min after performing each procedure in children with acute viral bronchiolitis.

acute viral bronchiolitis report no significant adverse effects or complications, indicating the safety of its application in these cases. ${ }^{6,7}$

It is widely known that the aspiration of the airways has as its main complications the mechanical trauma inherent to the procedure, which may cause mucosal irritation, nasal bleeding, and vomiting, ${ }^{11}$ as demonstrated in this study. The wide use of nasopharyngeal aspiration as the primary strategy for airway clearance was studied in children hospitalized with acute viral bronchiolitis, demonstrating its general indication and the restricted supporting evidence. ${ }^{10}$ The nasopharyngeal aspiration of infants with acute viral bronchiolitis as a routine in health-care teams, without a careful analysis of its necessity, increases the potential of this invasive procedure to generate new complications, including increased mucosal edema and obstruction, ${ }^{18}$ besides increasing the risk of other secondary infections. ${ }^{10}$

The severity of acute viral bronchiolitis was evaluated by using the Wood clinical score. The results showed that infants hospitalized for acute viral bronchiolitis classified with a moderate score (4-7) had a significant reduction in the presence of chest retractions and nasal bleeding in the clearance group as compared with the aspiration group. On the other hand, in infants classified with a mild (1-3) or high $(8-14)$ score, there were no differences between groups, indicating that the effects of retrograde rhinopharyngeal clearance may vary according to disease severity. Several studies ${ }^{7,8,14,19}$ have used clinical scores to demonstrate the clinical evolution of infants with acute viral bronchiolitis after a physiotherapy intervention. In addition, there is a current proposal to implement the clinical severity score to assess indications and contraindications for chest physiotherapy in children with acute viral bronchiolitis, suggesting that infants classified as moderate would benefit most from its indication compared with those with mild or severe conditions. ${ }^{20}$ Results from the present study also demonstrate that previous classification using the clinical severity score can contribute to a more precise indication and, consequently, to obtaining favorable clinical outcomes with the use of respiratory therapy techniques in infants with acute viral bronchiolitis.

The indication of respiratory physiotherapy in infants with acute viral bronchiolitis has been studied and discussed for a long time, ${ }^{21}$ although there is no consensus on the subject. Some studies have demonstrated favorable results with its use, $, 14,22$ whereas others have presented results without evidence of benefit. ${ }^{6,17,23}$ In fact, outcomes such as length of hospital stay and oxygen use do not seem to change with respiratory physiotherapy, regardless of the technique studied. ${ }^{5}$ However, signs of respiratory distress, such as wheezing and chest retractions, ${ }^{8,14}$ and cardiorespiratory parameters, such as heart rate and breathing frequency,, 14 besides the use of clinical scores, appear as favorable outcomes. Moreover, it seems well established that there are no adverse effects associated with the use of these techniques. ${ }^{6,7}$ In general, the difficulty in studying the effectiveness of respiratory physiotherapy techniques in infants with acute viral bronchiolitis seems to be related to the simultaneous use of different types of techniques, along with the inclusion of different levels of severity. ${ }^{15,20}$ It is well known that younger children have an immature pattern of respiratory muscle fibers and are consequently more prone to fatigue. ${ }^{20}$ Thus, there is a current tendency for using more modern techniques, such as prolonged slow exhalation and retrograde rhinopharyngeal clearance, compared with conventional techniques, such as postural drainage and percussion. In the present study, the use of retrograde rhinopharyngeal clearance alone, as an alternative to aspiration, showed positive results in relation to acute respiratory effort parameters and complications, without inducing adverse effects. Nevertheless, this study has some limitations, such as the impossibility of blinding subjects and therapists and the use of a short-term assessment. So, 


\section{Rhinopharyngeal Clearance in Infants With Bronchiolitis}

it is still necessary to evaluate the possible effects of the technique throughout the hospitalization.

\section{Conclusions}

The use of the retrograde rhinopharyngeal clearance technique in the clinical management of infants with acute viral bronchiolitis showed immediate positive effects on the occurrence of complications and signs of respiratory effort compared with nasopharyngeal aspiration. Children classified with a moderate clinical score appear to be the most benefited. The retrograde rhinopharyngeal clearance seems to be a safe technique and thus could be considered as a possible alternative in the management of infants with acute viral bronchiolitis and upper airway obstruction.

\section{ACKNOWLEDGMENTS}

We thank Fernanda Luisi for invaluable help during the project design and Ana Júlia Sidou Dias and Mariana Martini for help with data collection.

\section{REFERENCES}

1. Alvarez AE, Marson FA, Bertuzzo CS, Arns CW, Ribeiro JD. Epidemiological and genetic characteristics associated with the severity of acute viral bronchiolitis by respiratory syncytial virus. J Pediatr (Rio J) 2013;89(6):531-543.

2. Zentz SE. Care of infants and children with bronchiolitis: a systematic review. J Pediatr Nurs 2011;26(6):519-529.

3. American Academy of Pediatrics Subcommittee on Diagnosis and Management of Bronchiolitis. Diagnosis and management of bronchiolitis. Pediatrics 2006;118(4):1774-1793.

4. Teshome G, Gattu R, Brown R. Acute bronchiolitis. Pediatr Clin North Am 2013;60(5):1019-1034.

5. Roque i Figuls M, Gine-Garriga M, Granados Rugeles C, Perrotta C, Vilaro J. Chest physiotherapy for acute bronchiolitis in paediatric patients between 0 and 24 months old. Cochrane Database Syst Rev 2016;(2):CD004873.

6. Sánchez Bayle M, Martín Martín R, Cano Fernández J, Martínez Sánchez G, Gómez Martín J, Yep Chullen G, García García MC. [Chest physiotherapy and bronchiolitis in the hospitalised infant: double-blind clinical trial]. An Pediatr (Barc) 2012;77(1):5-11.

7. Rochat I, Leis P, Bouchardy M, Oberli C, Sourial H, Friedli-Burri M, et al. Chest physiotherapy using passive expiratory techniques does not reduce bronchiolitis severity: a randomised controlled trial. Eur J Pediatr 2012;171(3):457-462.

8. Gomes EL, Postiaux G, Medeiros DR, Monteiro KK, Sampaio LM, Costa D. Chest physical therapy is effective in reducing the clinical score in bronchiolitis: randomized controlled trial. Rev Bras Fisioter 2012;16(3):241-247.
9. Jacinto CP, Gastaldi AC, Aguiar DY, Maida KD, Souza HC. Physical therapy for airway clearance improves cardiac autonomic modulation in children with acute bronchiolitis. Braz J Phys Ther 2013; 17(6):533-540.

10. Jarvis K, Pirvu D, Barbee K, Berg N, Meyer M, Gaulke L, et al Change to a standardized airway clearance protocol for children with bronchiolitis leads to improved care. J Pediatr Nurs 2014;29(3):252257.

11. American Association for Respiratory Care. Nasotracheal suctioning 2004 revision \& update. Respir Care 2004;49(9):1080-1084.

12. Haddad ER, da Costa LCD, Negrini F, Melosa LM. Abordagens fisioterapêuticas para remoção de secreções das vias aéreas em recém-nascidos: relato de casos. Pediatria (São Paulo) 2006;28(2):135140. Article in Portuguese.

13. Wood DW, Downes JJ, Lecks HI. A clinical scoring system for the diagnosis of respiratory failure: preliminary report on childhood status asthmaticus. Am J Dis Child 1972;123(3):227-228.

14. Postiaux G, Louis J, Labasse HC, Gerroldt J, Kotik AC, Lemuhot A, Patte C. Evaluation of an alternative chest physiotherapy method in infants with respiratory syncytial virus bronchiolitis. Respir Care 2011;56(7):989-994.

15. Pupin MK, Riccetto AG, Ribeiro JD, Baracat EC. Comparison of the effects that two different respiratory physical therapy techniques have on cardiorespiratory parameters in infants with acute viral bronchiolitis. J Bras Pneumol 2009;35(9):860-867.

16. S Gonçalves RA, Feitosa S, de Castro Selestrin C, Valenti VE, de Sousa FH, Siqueira AAF, et al. Evaluation of physiological parameters before and after respiratory physiotherapy in newborns with acute viral bronchiolitis. Int Arch Med 2014;7(1):3.

17. Gajdos V, Katsahian S, Beydon N, Abadie V, de Pontual L, Larrar $\mathrm{S}$, et al. Effectiveness of chest physiotherapy in infants hospitalized with acute bronchiolitis: a multicenter, randomized, controlled trial. PLoS Med 2010;7(9):e1000345.

18. Fischer GB, Teper A, Colom AJ. Acute viral bronchiolitis and its sequelae in developing countries. Paediatr Respir Rev 2002;3(4): 298-302.

19. Nicholas KJ, Dhouieb MO, Marshall TG, Edmunds AT, Grant MB An evaluation of chest physiotherapy in the management of acute bronchiolitis: changing clinical practice. Physiotherapy 1999;85(12): 669-674.

20. Postiaux G, Zwaenepoel B, Louis J. Chest physical therapy in acute viral bronchiolitis: an updated review. Respir Care 2013;58(9):15411545.

21. Webb MS, Martin JA, Cartlidge PH, Ng YK, Wright NA. Chest physiotherapy in acute bronchiolitis. Arch Dis Child 1985;60(11): 1078-1079.

22. Castro G, Remondini R, Santos AZ, Prado C. Analysis of symptoms, clinical signs and oxygen support in patients with bronchiolitis before and after chest physiotherapy during hospitalization. Rev Paul Pediatr 2011;29(4):599-605.

23. Bohé L, Ferrero ME, Cuestas E, Polliotto L, Genoff M. [Indications of conventional chest physiotherapy in acute bronchiolitis]. Medicina 2004;64(3):198-200 